\title{
Reflexiones sobre Cenicienta
}

\author{
Ricardo Miguel Haye"
}

Que la investigación básica sobre la radio, en general, resulta insuficiente es algo reconocido por la práctica totalidad de los estudiosos de la comunicación. El tema de la publicidad radiofónica, obviamente, no escapa a las generales de la ley, aunque constituye un campo sobre el que se puede verificar la existencia de un número significativo de estudios de investigación aplicada.

Probablemente resulte ocioso discurrir por el análisis del carácter funcionalista de estos trabajos. En cambio, nunca será inadecuado reflexionar acerca del papel que la investigación universitaria puede desempeñar en rumbo a clarificar nociones más allá de las imperativas demandas que formula el mercado, elevado actualmente a categorías celestiales.

La necesidad de consideraciones sistemáticas se justifica incluso desde intereses estrictamente materiales. Basta pensar que pese a la extraordinaria implantación de la televisión en el mercado de los anuncios, la inversión publicitaria en radio también experimentó un crecimiento notable descle que el medio audiovisual sacara carta de residencia en la mayoría de los hogares del globo. Para muestra, un botón: si en 1948, antes de la

* Profesor de la Universidad Nacional del Comahue, UNC (Río Negro, Argentina) y miembro de la Red COES. 
masiva invasión catódica, la radio estadounidense facturaba 562 millones de dólares, cuatro décadas más tarde esa cifra trepaba ya a los 7000 millones de dólares.

No obstante, la atención concedida por los investigadores al invento de Marconi ha sido tan exigua como para motivar la queja de los más eminentes hombres de la publicidad. Al propio David Ogilvy se le ha escuchado decir alguna vez que «la radio es la Cenicienta de los medios».

Por otra parte, tampoco la formación universitaria en publicidad parece ocuparse adecuadamente del soporte radiofónico, al punto que alguna de las carreras españolas no lo incluyen entre sus asignaturas básicas. Los alumnos pueden graduarse entonces, aunque no hayan incorporado sistemáticamente una cantidad de fundamentos básicos acerca de un medio que, en España, factura por encima de los 30.000 millones de pesetas anuales.

Entre esas nociones puede citarse un factor tan importante en el establecimiento de la imagen de una emisora y la formación de su audiencia como la programación, elemento que determina de modo preponderante la sintonía de una estación u otra. Y dentro de la programación, aspectos destacados como los géneros y las estructuras de producción (formatos) utilizados.

Por otra parte, la comprensión acabada del fenómeno de la radio exige algo más que el análisis de su fase de emisión. Los estudios de recepción deben ampliarse más allá de los consabidos datos estadísticos que configuran los ratings. Las cifras por sí mismas, no pueden definir el nivel de receptividad de los oyentes, las demandas que cubre un determinado mensaje, las necesidades que deja sin atender, la resignificación que formulan los públicos. En definitiva, el grado de utilidad que la propuesta radiofónica posee al llegar a destino.

Por fin, el fenómeno publicitario en la radio no puede estudiarse prescindiendo de las mutaciones sociales producidas en las últimas décadas. Y con ello no solo queremos significar la pérdida de protagonismo excluyente que la radio supo tener. También aludimos a los modos en que se están reconfigurando los comportamientos sociales y los hábitos de consumo de la gente. La aparición de grandes tiendas o «mega-stores» e, incluso, la com- 
pra a distancia mediante ordenadores están modelando una nueva realidad a la que los medios deberán adaptarse. Y hablar de los medios, supone ya la exigencia de prever las modificaciones y articulaciones que el paisaje mediático sufrirá a partir del proceso de convergencia con la telemática.

Como se puede advertir con facilidad, ante los estudiosos del tema se abre un amplio abanico temático que reclama una atención capaz de trascender los aspectos puramente instrumentales e inmediatistas de la capacitación y la investigación publicitaria.

Características de la publicidad radial

The Pretesting Company es un grupo de Englewood, New Jersey, dedicado a la investigación publicitaria. Sus relevamientos le permitieron comprobar que sólo el $22 \%$ de los comerciales de radio comunican su mensaje. Pero también verificaron que casi el $70 \%$ de los comerciales de TV pasan inadvertidos; que dos de cada tres anuncios impresos se olvidan rápidamente y que sólo una de cada diez carteleras al aire libre es leída.

Un estudio de Radio Recall Research demostró que un comercial radiofónico memorable incrementa en 300 por ciento el promedio de la audiencia capaz de recordarlo. Cuando el uso de la radio es recomendable, la agencia y el cliente comparten la responsabilidad de que el anuncio sea memorable (cerciorándose de que se hará el mayor esfuerzo creativo para lograrlo).

Algunos autores han anotado varias de las expectativas válidas para la publicidad radiofónica, entre las que pueden mencionarse:

aumentar la percepción de la marca;

aumentar el reconocimiento del nombre;

aumentar el alcance en el segmento de mercado actual;

establecer el alcance en segmentos de mercados adicionales;

posibilitar la introducción en un nuevo mercado;

desarrollar nuevos centros de distribución;

adquirir una frecuencia adicional;

reforzar otros medios; 
apoyar promociones de centros comerciales;

conjuntar dos o más anunciantes.

Pero estas expectativas resultan igualmente válidas para otros medios. Sin embargo, existen algunas capacidades que la radio destaca más, por ejemplo la promoción de mercados locales (a través de emisoras de baja potencia); los anuncios de productos o servicios especiales (en la radiofórmula, que se acerca así a lo que en medios impresos se designa como «house organs»); reaccionar con prontitud frente a la competencia (por la menor complejidad de elaboración de los spots).

Asimismo, la radio cuenta con un valor relevante: la calidad del contacto medio-público. Esta variable asume un carácter destacado, sobre todo en sociedades que asignan a la radiodifusión uno de los mayores índices de credibilidad.

Por su propia naturaleza, el medio ofrece como ventajas:

Una extensa gama de recursos.

La flexibilidad en tiempo y espacio.

Su carácter íntimo y personal.

Su capacidad de actuar sobre la imaginación.

La comodidad de su uso. La radio es dócil, siempre a mano, barata.

Y plantea estas desventajas:

Sus mensajes están inscriptos en el tiempo, son fugaces. No admite serios razonamientos, ni largas argumentaciones. Se oye más que se escucha.

No puede presentar el producto físico.

A riesgo de resultar machacón, debe insistirse en que estas nociones, apenas esbozadas, requieren de una minuciosa andadura por parte de quien aspire a desenvolverse airosa y eficazmente a través del éter.

Evolución de los estilos publicitarios

Podría uno repasar las reglas instauradas hace años ya por las agencias y advertiría la presencia de estilos que suscitan fuertes evocaciones de las corrientes conductistas aplicadas a la mass comunication research. Se 
encontraría también con la sorpresa que arrojan las paradojas: junto a un modelo publicitario que expresa una intencionalidad fuertemente impositiva, aparecen los reclamos de los patrones a sus creativos para que desarroIlen un estilo basado en la amabilidad. La empresa de David Ogilvy planteaba que «hay que tener buena educación y no hacer jamás el payaso» y que nunca debe redactarse «un anuncio que nos desagradaría que leyese nuestra propia familia».

Estas nociones, sin embargo, se han visto rebasadas por el paso del tiempo y el público tiene internalizado ya un modelo publicitario más agresivo que el de décadas pasadas. Un ejemplo paradigmático podría ser el de los spots televisivos de «Radical Fruits», pero sólo es un caso entre tantísimos otros.

Un viejo folleto de la Radio Advertising Bureau exigía a los redactores que no escribiesen en forma poética, una imposición que difícilmente estuvieran dispuestos a suscribir o aceptar los creativos contemporáneos.

En fin, que los cambios merecen ser estudiados y conocidos. Y que el auxilio de otros saberes no puede ser menospreciado, dado que en el marco de ese espacio de vital intersección de disciplinas que es la comunicación encontraremos los insumos necesarios para articular histórica, social, cultural, económica y políticamente esa evolución.

Componentes de una tabla de estilos.

El análisis de los mensajes publicitarios radiofónicos exige la consideración de una serie de elementos y características tales como: participación de la palabra, número de voces intervinientes, utilización de música o efectos de sonido, duración del aviso, etc. La ponderación reclama también el estudio de las formas que arropan el anuncio: humorísticas, dramáticas, expositivas.

Al reflexionar sobre estos aspectos, se advierte la necesidad de orientar la investigación a través de una tabla de estilos, igual que ocurre con los trabajos sobre publicidad en televisión.

En ocasión de un trabajo elaborado hace algunos meses, el autor se vio 
ante la necesidad de construir esa tabla, dado que, o bien no existe, o bien no supo dar con ella.

El único antecedente disponible, además de las tablas de estilo aplicadas a la publicidad televisiva, surgía de un trabajo del francés Jean Pierre Bacelon, responsable de Marketing de la Comunicación en el grupo «Información y Publicidad» (IP).

01. «La tranche de vie» o dramatización de un episodio de la vida real. Es la forma más antigua de la comunicación sonora e históricamente está inspirada en las primeras obras por episodios realizadas en la radio por las gentes de teatro. El oyente entiende, sin ninguna ambigüedad, que este producto radiofónico es, en realidad, un «sketch» publicitario y, probablemente, esta es la forma de publicidad que se aleja más del tono del programa, sobre todo desde que desaparecieron de la programación los espacios dramáticos, desplazados por el predominio de los animadores.

02. La llamada. Agrupa al conjunto de los mensajes que incitan al oyente a participar en una determinada acción comercial. Su origen hay que buscarlo en el antiguo «reclamo» y su lenguaje es el que corresponde a las ofertas especiales, a las promociones, a los precios sin competencia. La mayor parte de estos anuncios están enmarcados en «jingles» $o$ indicativos sonoros que dan a este tipo de publicidad un color muy específico.

Estas «cuñas» forman parte integrante de las emisoras comerciales francesas del mismo modo que los carteles forman parte de la calle; y los oyentes, sabedores de que cada día se producen promociones que pueden interesarles, no se sorprenden al descubrir en la radio una ocasión de remediar la baja de su poder adquisitivo y una oportunidad de aprovechar las buenas «gangas» que la radio anuncia.

03. El testimonio. Los anunciantes ceden la palabra a los consumidores para que sean estos quienes hablen de sus productos. Por supuesto, hay testimonios verdaderos y los hay falsos, pero la credibilidad depende en mayor medida del juicio de los oyentes que de las intenciones de los publicitarios, y desde que está en vigor este tipo de publicidad el público ha aprendidò y discierne mejor que nadie entre lo auténtico y la manipulación, de tal manera que resulta inútil y baldío el intento de engañarle. 
04. La argumentación. Bajo esta forma se recogen los mensajes que responden a una lógica demostrativa del producto, que intentan la respuesta, más o menos técnica, a un problema y que ofrecen una solución, más o menos ajustada a la realidad. Esta publicidad pone por delante y da cuenta de las características del producto, lo cual supone y aún presupone la seriedad del anunciante que asegura que su producto es específicamente distinto de los productos competidores. Desde luego, las emisoras ejercen un control riguroso sobre la veracidad de los argumentos empleados en este tipo de publicidad: no les interesa aceptar publicidad engañosa, cuya difusión iría en contra de la propia emisora. He aquí el riesgo de este tipo de anuncios: mientras que el anunciante puede, eventualmente, perder un cliente defraudado, la emisora perdería para siempre a un oyente engañado.

05. La descripción. Se incluyen en esta categoría los mensajes que presentan de manera objetiva la apariencia del producto, sus elementos, sus partes o su composición. Esta es, ciertamente, una forma publicitaria difícil de traducir al lenguaje radiofónico; por lo general y para superar este inconveniente, los anunciantes describen «radiofónicamente» al producto, a la vez que lo «enseñan» visualmente en otros medios, como la televisión, el cine o incluso la prensa.

06. El humor. Este tipo de comunicación publicitaria impregna el mensaje de un cierto clima de simpatía que, en la intención del anunciante, trasciende a la marca o al producto, los cuales se benefician de esta sensación optimista y positiva, perfectamente captada por el oyente. Ciertamente, se trata de una técnica difícil, arriesgada y de muy problemático éxito.

07. La evocación. En este último apartado es donde, sin duda, se advierte de manera más nítida el sello de la creación publicitaria. Aquí, el anunciante más que imponerse intentar seducir; más que ofrecer al oyente un argumento, pretende convertirle en partícipe de una imagen. En efecto, nos encontramos en el área de la creación sonora por excelencia, de la fabricación de un mundo imaginario con solo el poder del sonido, razones por las cuales esta forma de publicidad es la de más fácil inserción en un programa de radio, rivaliza con la creatividad del propio programa y los animadores se apoyan en estos mensajes para potenciar su trabajo ante el micrófono. 
Pero existen, además, otros estilos que podemos incorporar a esta clasificación:

08. La publinota. Se trata de publicidad «disfrazada». Por ejemplo, la que se canaliza en una entrevista presuntamente periodística al dueño de un restaurante, durante la cual se suministra el nombre del local y se incluyen referencias a su ubicación o tipo de servicios que ofrece. Este tipo de promoción suelen realizarla los conductores de programas sin hacer explícita mención a que se trata de un mensaje comercial.

09. Las «donas», es decir anuncios grabados con un hueco en el centro para intercalar mensajes en vivo.

Luego de trabajar con los conceptos anteriormente descriptos hemos intentado reunirlos con los propios, sedimentarlos y macerarlos en una amalgama capaz de aplicarse en la tarea analítica.

Al hacerlo entendimos que el «estilo» publicitario es el resultante de la combinación de los aspectos morfológicos del mensaje, así como de la naturaleza y el tipo de su discurso.

De este modo, al interior de cada uno de estos componentes, hemos considerado las categorías que se detallan:

Taxonomía del discurso:

Texto en seco. El mensaje verbal carece de cualquier otro acompañamiento sonoro (música, efectos).

Texto con música instrumental de fondo.

Texto con música cantada de fondo.

Texto acompañado por efectos sonoros.

Texto acompañado de música y efectos sonoros. «Jingle».

Fuente del discurso:

Texto testimonial. El mensaje incluye opiniones, testimonios de los consumidores o usuarios del producto que se anuncia.

Texto de personaje público. El mensaje utiliza la fama, prestigio, credibilidad, etc. de un personaje reconocido en apoyo del producto que promociona.

Texto del locutor. 
Texto de intérpretes. El mensaje emplea actores o locutores en tanto que «personajes». Estas voces se distinguen del carácter neutro en cuanto a personalidad que reviste el texto del locutor.

«Habla» el producto. Mediante el recurso de humanización, el producto adquiere voz propia para expresar sus ventajas y bondades.

Publinota. Se trata de publicidad «disfrazada». El presunto tratamiento periodístico, a través de una entrevista, o un comentario esconde una intención promocional por cuanto incluye mención(es) a un producto o servicio. Tipo de discurso:

Problema--Solución. El aviso plantea una dificultad que el producto anunciado viene a resolver.

Texto humorístico.

«Slices of life» (Trozos de vida) o recreación dramatizada.

Texto informativo-descriptivo. Predominancia de datos dirigidos a presentar de manera objetiva la apariencia del producto, sus elementos, sus partes o su composición.

Texto explicativo-argumentativo. Predominancia de explicación técnica sobre la composición del producto, la forma en que fue creado/producido, las razones a que atiende su creación/producción, la utilidad que ofrece, etc.

Texto admirativo. Predominancia de terminología valorativa acerca de las virtudes del producto.

Aunque resulte obvio, conviene aclarar que estas categorías difícilmente se encuentren en términos químicamente puros. Las más de las veces aparecen entremezcladas.

La confección de tablas como estas (u otras más complejas) pueden resultar de gran ayuda para verificar las características que se imprimen a los anuncios en términos de ritmo de locución, complejidad de producción, participación de los elementos que conforman el discurso radiofónico, cantidad de palabras incluidas en un mensaje, utilización de términos abstractos o concretos, contrastes entre voz y fondo, distribución de los avisos según criterios de duración, ritmo o calidad de realización, hora de emisión, cantidad de anuncios grabados o en directo, etc. 
De este modo, podría estimarse también la totalidad de la publicidad emitida en una emisora, o en uno de sus programas, o en dos programas similares de radios diferentes, a fin de establecer el perfil del público-objetivo, la existencia de campañas largas y poco intensas o de otras que concentran gran cantidad de anuncios en poco tiempo.

Existen vacíos teóricos y es la Universidad quien debe asumir la responsabilidad de cubrirlos mediante una nutriente conceptualización crítica, acorde con el papel histórico que la investigación ha adquirido en sus claustros. 